\title{
Molecular genetic diagnosis of autosomal dominant polycystic kidney disease in a newborn with bilateral cystic kidneys detected prenatally and multiple skeletal malformations
}

\author{
Alberto E Turco, Ezio M Padovani, Gian Paolo Chiaffoni, Bernard Peissel, \\ Sandro Rossetti, Alma Marcolongo, Linda Gammaro, Giuseppe Maschio, \\ Pier Franco Pignatti
}

Institute of Biological Sciences and Genetics, The University of Verona School of Medicine, University Hospital Polyclinic B Roma, Strada Le Grazie, 37134 Verona, Italy.

A E Turco

B Peissel

S Rossetti

P F Pignatti

\section{Department of} Pediatrics, Section of Neonatal Pathology, The University of Verona School of Medicine, Verona, Italy.

E M Padovani

G P Chiaffoni

\section{Department of} Obstetrics and Gynaecology, University of Verona School of Medicine,

Verona, Italy.

A Marcolongo

Division of Medical Nephrology,

University of Verona

School of Medicine,

Verona, Italy.

L Gammaro

G Maschio

Correspondence to Dr Turco.

Received 4 July 1992. Revised version accepted 2 September 1992.

\begin{abstract}
We report a case of an unusual prenatal presentation of polycystic kidneys associated with multiple skeletal limb defects, including polydactyly, syndactyly, bilateral agenesis of the tibia, and club foot. The ultrasonographic picture was consistent with a diagnosis of polycystic kidney disease, either the adult onset autosomal dominant type (ADPKD) or the early onset autosomal recessive form (ARPKD). However, there was a positive family history for ADPKD. Linkage analysis was performed in 10 family members, of whom four were affected, using six flanking DNA markers tightly linked to the PKD1 locus on chromosome 16p, and one marker linked to the putative PKD2 locus on chromosome 2 p. Lod score determinations indicated that the affected gene in the family is most likely PKD1. The patient inherited the disease linked haplotype from his affected mother.

( $¥$ Med Genet 1993;30:419-22)
\end{abstract}

Autosomal dominant polycystic kidney disease (ADPKD) is one of the most common hereditary single gene disorders in humans, occurring in approximately 1 in 500 to 1 in 1000 live births. The biochemical defect of the disease is as yet unknown. The gene whose mutations are responsible for the most frequent form of the disease has been named PKD1 and is located on the short arm of chromosome $16 .^{1}$ It has been estimated that around 1 to $4 \%$ of families with ADPKD have mutations unlinked to chromosome 16 markers, thus confirming previous reports of genetic heterogeneity. ${ }^{23}$ Recently, a putative PKD2 locus has been tentatively mapped to chromosome $2,{ }^{4}$ even though there has been no other confirmation of linkage to this locus in an ADPKD family. ADPKD is typically a late onset disorder, the first clinical symptoms usually occurring between 40 and 50 years of age. ${ }^{5}$ Nevertheless, there have been several reports of ADPKD diagnosed by ultrasonography in a newborn or infant and fewer cases detected prenatally. ${ }^{67}$

Autosomal recessive polycystic kidney disease (ARPKD), the infantile type of the disease, commonly develops in infancy or childhood, ${ }^{8}$ and is caused by mutation(s) in a gene still unknown, but different from PKD1.9
We report here an unusual case of bilateral polycystic kidneys, detected prenatally by ultrasonography, in a newborn with multiple skeletal malformations and a family history of ADPKD.

\section{Case report}

An obstetric ultrasound examination was performed on a 28 year old woman with ADPKD (subject III-15 in fig 1) at 20 weeks' gestation. The fetal ultrasonography showed bilateral microcystic kidneys. A male infant was delivered by caesarean section because of breech presentation at 40 weeks' gestation. At birth, the baby had enlarged and low set ears, micrognathia (fig 2A), normal weight and head circumference, and slightly reduced length. The abdomen appeared significantly and irregularly enlarged with easily palpable kidneys. No respiratory distress was present. The urine was normal. At birth, a sonogram showed enlarged, diffusely hyperechogenic kidneys (about $7 \mathrm{~cm}$ in length), with tiny, multiple, bilateral cortical cysts and disappearance of the structural differentiation pattern of the renal cortex and medulla. Several larger cortical cysts later appeared, of which the largest was localised at the inferior pole of the left kidney and had a diameter of more than $15 \mathrm{~mm}$ at 3 months of age and of $25 \mathrm{~mm}$ at 5 months. No liver cysts or bile duct abnormalities were detected. The baby's blood pressure, renal and liver functions were normal at 5 months of age. He has been successfully treated for a urinary tract infection.

In addition to the renal involvement, the newborn had complex skeletal malformations including bilateral complete syndactyly of the hands and feet, bilateral polydactyly of the feet (seven metatarsal phalangeal structures on the right and eight on the left), with fusion of the soft tissues, shortening and bowing of the lower limbs, bilateral agenesis of the tibia, and bilateral club foot (fig $2 B$ and C, fig $3 B$ and $C$ ). No vertebral, hip, rib, or skull defects were detected by $x$ ray examinations (fig $3 \mathrm{~A}$ ). A cerebral CT scan showed no brain defects. Karyotypic analysis showed no chromosome abnormalities. The extended prometaphase chromosome banding pattern was normal. There was no history of skeletal malformations in either the maternal or paternal families. The 


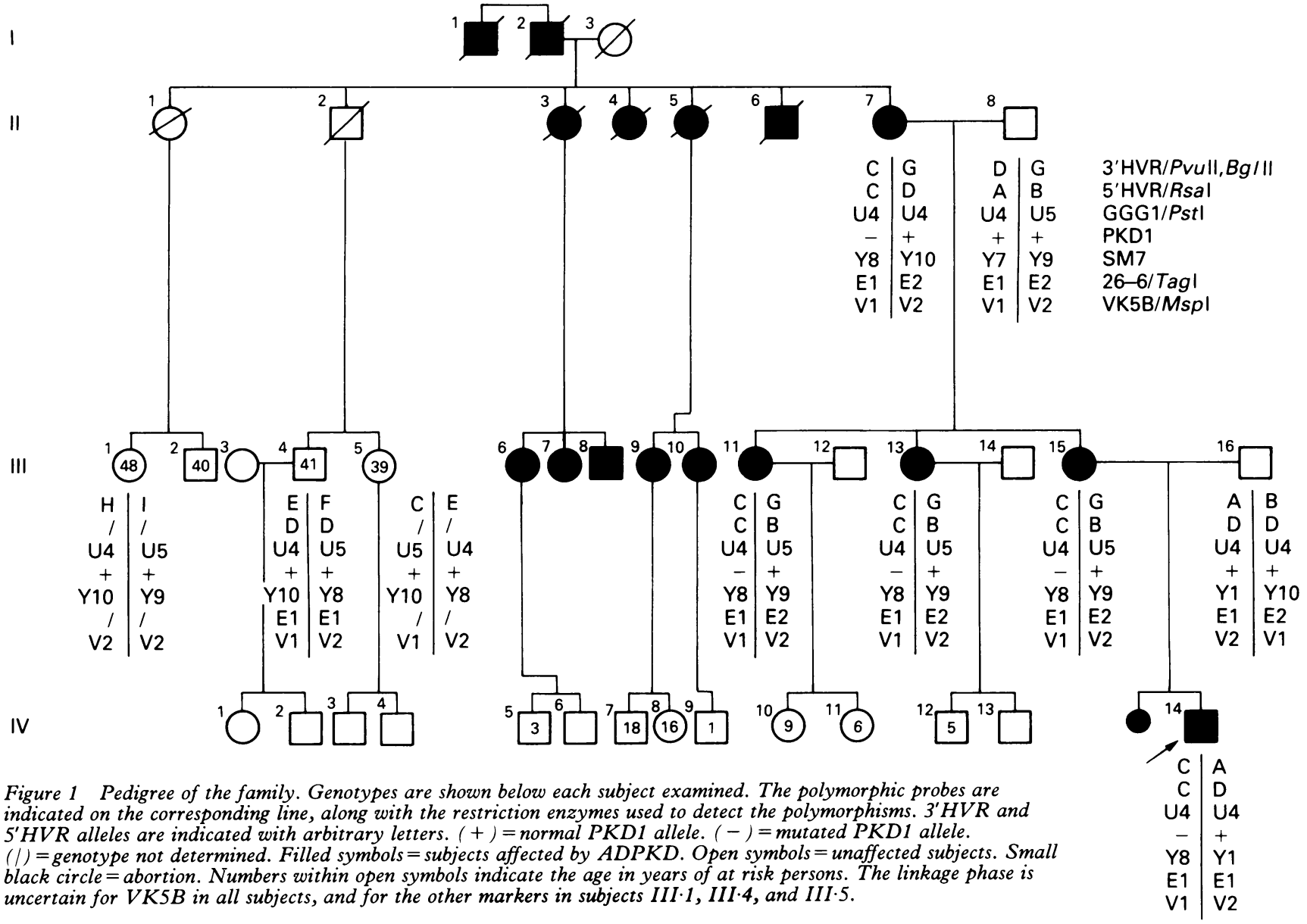
uncertain for VKSB in all subjects, and for the other markers in subjects III.1, III.4, and III.5.
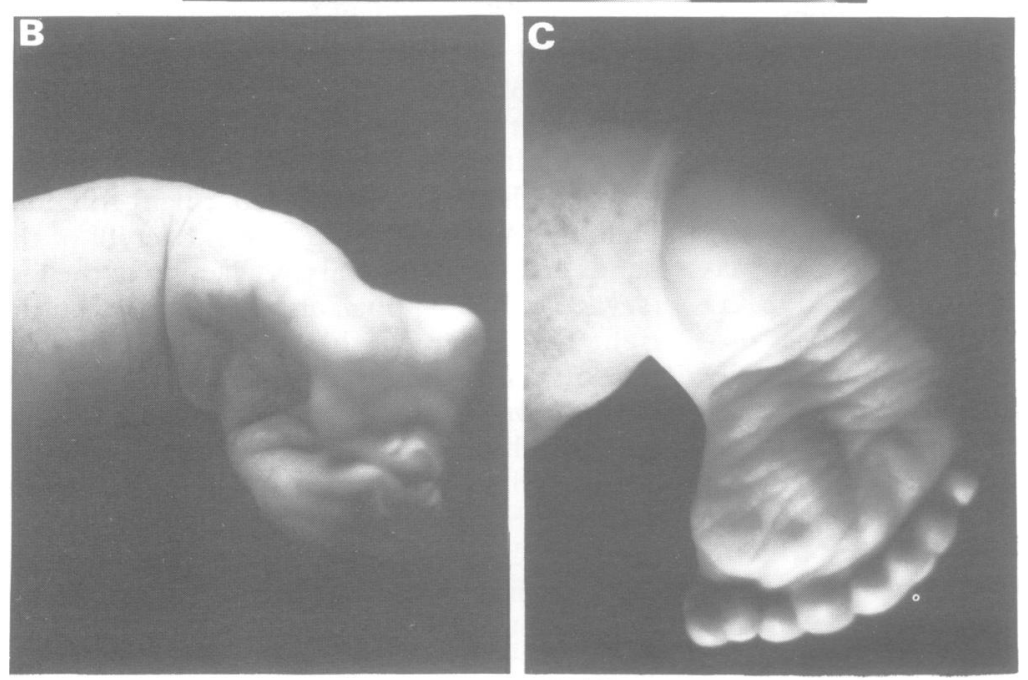

Figure 2 The patient at 3 months of age showing $(A)$ low set ears and micrognathia, (B) polydactyly-syndactyly of the left hand, (C) polydactyly of the left foot. family comes from north-eastern Italy and there is no indication of consanguinity. Further information on the family is available on request from the authors.

The genotypes obtained at the various $16 \mathrm{p}$ polymorphic loci $^{310}$ are shown in fig 1 under each subject tested. The other affected members in generation III were unwilling to cooperate. The disease appears to segregate with the haplotype (tel-3'HVR/5'HVR-GGG1PKD1(-)-SM7-26-6-VK5-cen): C/C/U4/Y8/ E1/V1(or V2). No recombination events were identified between $P K D 1$ and any of the informative markers used.

An example of the results obtained with the newly described SM7 microsatellite marker ${ }^{11}$ is shown in fig 4 . Five different alleles were detected in this family. Allele Y8 segregates with the disease.

The pairwise lod scores for linkage to $P K D 1$ are shown in the table. The maximum lod scores $(Z \max )$ for informative markers $3^{\prime} \mathrm{HVR}$, 5'HVR, SM7, and GGG1 were 0.983, 1.074, $0 \cdot 888,0 \cdot 197$, respectively, obtained at $\theta=0.0$ for $3^{\prime} \mathrm{HVR}, 5^{\prime} \mathrm{HVR}$, and SM7, and at $\theta=0.02$ for GGG1. The lod scores for 26-6 were slightly negative, owing to the low informativity of the marker in the family. The lod scores for VK5B were equal to zero for all values of $\theta$ owing to the complete uninformativeness of this probe. The highest relative likelihood (odds ratio) for linkage to $P K D 1$ (5'HVR) was 11.85 to 1 . The multipoint lod score for linkage of the disease to the PKD1 gene in the family, considering simultaneously 


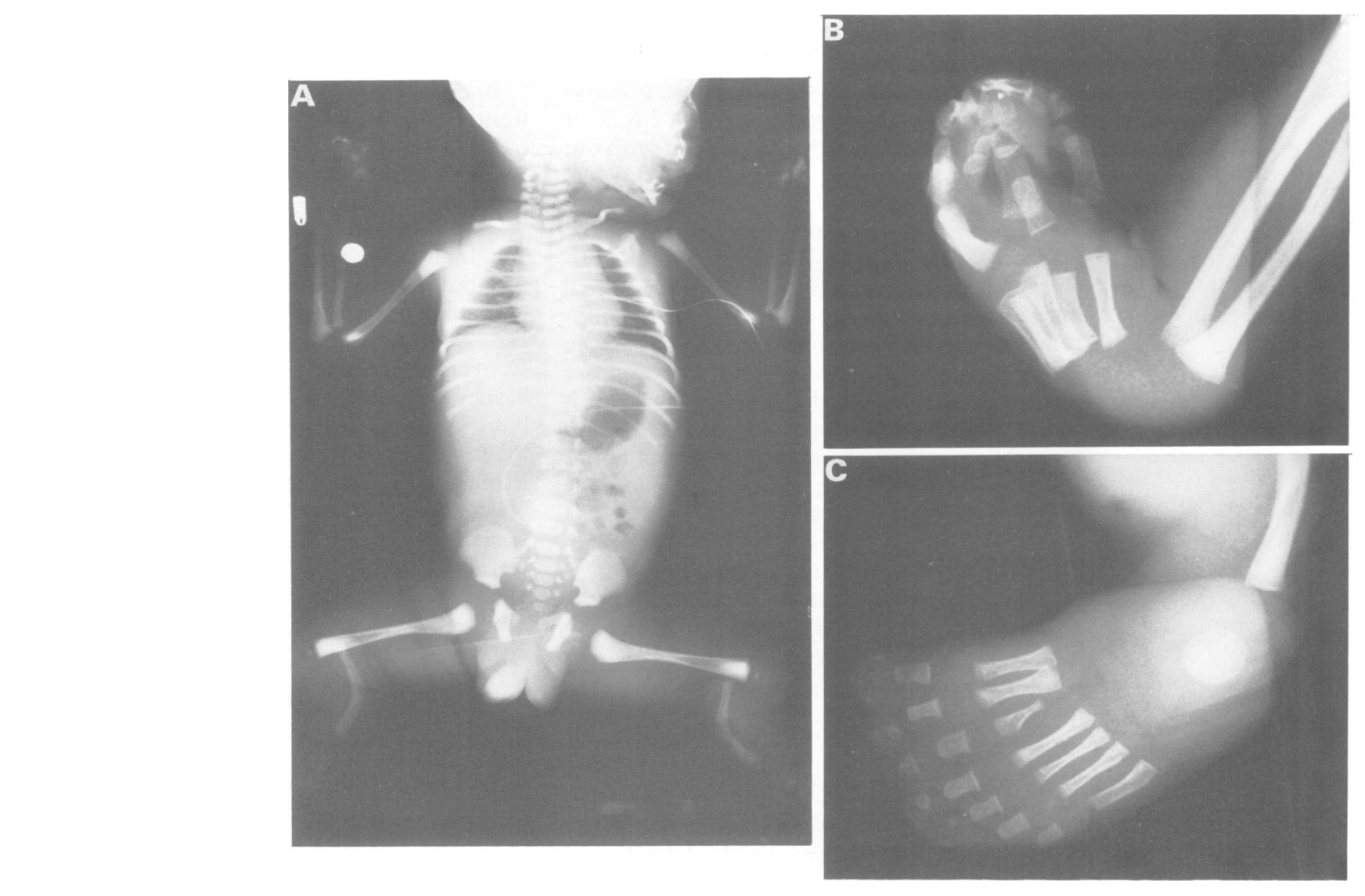

Figure 3 Radiographs of the patient showing (A) whole body (anteroposterior view), (B) left hand, (C) left foot. Note the absence of the tibiae.

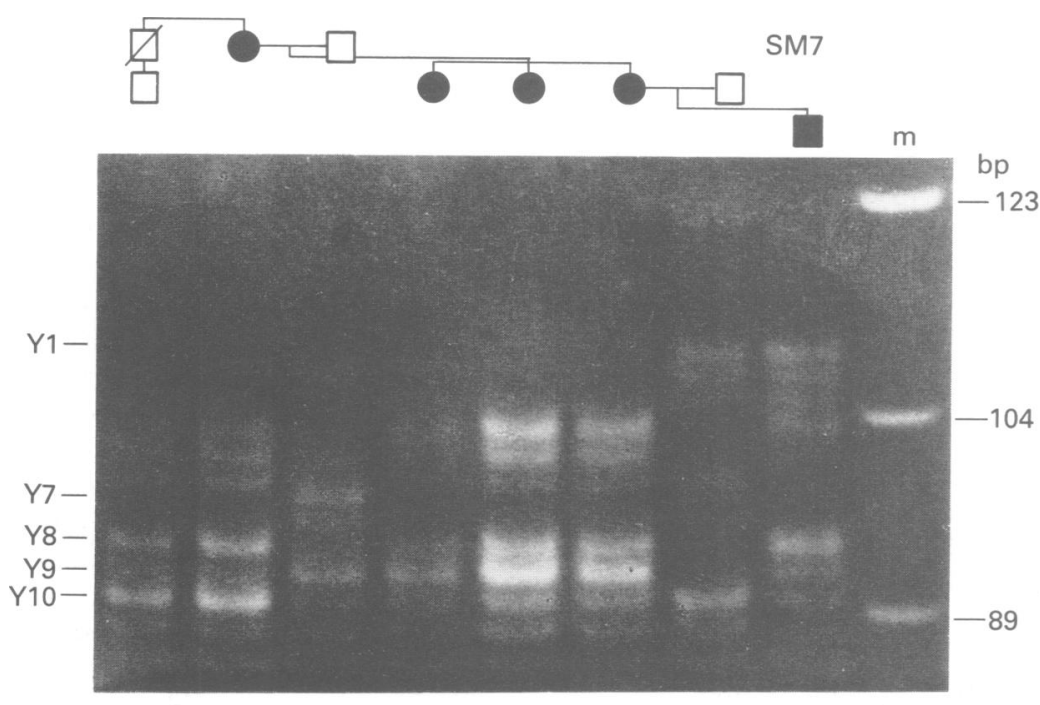

$\begin{array}{llllllll}1 & 2 & 3 & 4 & 5 & 6 & 7 & 8\end{array}$

Figure 4 Direct analysis of SM7 genotypes in the family after PCR and ethidium bromide staining. Lane 1 III 4 , lane 2 II $\cdot 7$, lane $3 I I \cdot 8$, lane $4 I I I \cdot 11$, lane 5 III 13 , lane $6 \mathrm{III} \cdot 15$, lane $7 \mathrm{III} \cdot 16$, lane $8 \mathrm{IV} \cdot 14 . \mathrm{M}=$ molecular weight markers in base pairs $(b p)$. Alleles are indicated on the left hand side.

Two point lod scores for linkage to PKD1 or PKD2.

\begin{tabular}{lcrrrrrrr}
\hline ADPKD & \multicolumn{7}{c}{ Recombination fraction $(\theta)$} \\
\cline { 2 - 8 }$v$ & 0.0 & 0.001 & 0.02 & 0.05 & \multicolumn{1}{c}{0.10} & 0.20 & Zmax & $\theta \max$ \\
\hline 3'HVR $^{\prime}$ 'HVR & 0.983 & 0.960 & 0.942 & 0.880 & 0.774 & 0.552 & 0.983 & 0.00 \\
GGG1 & 1.074 & 1.052 & 1.028 & 0.957 & 0.837 & 0.591 & 1.074 & 0.00 \\
SM7 & 0.196 & 0.196 & 0.197 & 0.195 & 0.191 & 0.169 & 0.197 & 0.02 \\
26-6 & 0.888 & 0.841 & 0.854 & 0.802 & 0.711 & 0.517 & 0.888 & 0.00 \\
VK5B* & -0.152 & -0.150 & -0.126 & -0.096 & -0.059 & -0.020 & 0.000 & 0.50 \\
YNH24 & 0.000 & 0.000 & 0.000 & 0.000 & 0.000 & 0.000 & & \\
\hline
\end{tabular}

* The VK5B linkage data were completely uninformative; therefore the lod scores equal zero for all values of $\theta$. the hypervariable flanking markers $5^{\prime} \mathrm{HVR}$ and SM7, was 0.927 , indicating that the odds for linkage were 8.46 to 1 . The lod scores obtained with the VNTR probe YNH24 $(Z=-3.007$ at $\theta=0.01$ ) indicated absence of linkage to the putative PKD2 locus on chromosome 2. These results strongly suggest that the disease is most likely of the PKD1 type.

\section{Discussion}

The finding of a fetus with polycystic kidneys suggests the diagnosis of the perinatal form of autosomal recessive polycystic kidney disease (ARPKD). Given that ADPKD and ARPKD may be clinically and ultrasonographically indistinguishable, the positive family history of ADPKD, and the unusual skeletal features, the issue in this case was whether the patient had the rarer and more severe recessive form, or the adult type disease, or still another unrelated disorder. A few cases of adult type ADPKD have been reported so far with early onset in childhood or even in the neonate. ${ }^{6}$ Fewer cases have been diagnosed in the fetus. For example, in a large series of paediatric nephrology patients surveyed over a 15 year period, 22 ADPKD cases were observed with onset before the age of 15 , of which two cases were diagnosed prenatally. ${ }^{12}$

By means of molecular haplotype identification, we have determined the presence of the ADPKD carrying chromosome in the family, showing that a PKD1 gene mutation was segregating in the affected family members, and that the same gene was inherited by the 
proband. Negative lod scores were obtained with probe $\mathrm{YNH} 24$ for linkage to $P K D 2$, indicating absence of linkage to this putative second PKD locus. The finding that $P K D 1$ is segregating in the family is consistent with our previous report on six large ADPKD kindreds. ${ }^{3}$

SM7, a recently developed microsatellite polymorphism tightly linked to $P K D 1$, increases the informativeness of proximal markers, and allows a more rapid and nonradioactive linkage analysis by $P C R$ in ADPKD families. Furthermore, being closer to $P K D 1$ than any of the existing markers, it carries the least possible risk of recombination with the disease locus, and represents a better starting point for the identification of the PKD1 gene by positional cloning.

ARPKD is rare, ${ }^{13}$ and there are usually no associated malformations. Liver involvement is considered an obligatory finding, with bile duct proliferation and periportal fibrosis. ${ }^{14}$ The lack of hepatic involvement in the patient would exclude the diagnosis of ARPKD; moreover, the presence of the ADPKD gene makes it highly unlikely that the disease might be the recessive variety.

The occurrence of multiple congenital skeletal malformations in association with ADPKD has not been previously described to the best of our knowledge. In this family, it seems to represent a sporadic event, associated by chance with ADPKD. We could reasonably exclude the use of known teratogens, drugs, alcohol, ionising radiation, and infection during the course of the pregnancy. A case of fetal onset ADPKD diagnosed by ultrasonography has been reported in which the baby was born with congenital absence of the right hand. ${ }^{6}$ Loh et $a l^{15}$ reported an association between infant onset ADPKD and hypertrophic pyloric stenosis.

Factors leading to early manifestations of ADPKD are unknown. The involvement of modifying alleles has been postulated ${ }^{16}$ to explain 'familial' clustering of early onset ADPKD. However, in this case there is no evidence of early onset of the disease in the living affected members. For the dead members who were affected, no information is available as to the age of onset of the disease. The search for the PKD1 gene is in progress. ${ }^{17}$ Once the PKD1 gene is known, it will be of great interest to determine whether particular mutations may also be responsible for an earlier onset subgroup of the disease. ${ }^{18}$

The prognosis for ADPKD in the fetus and in the infant is not easily predictable, but it is better than for ARPKD. ${ }^{6}$ Early diagnosis of ADPKD allows for proper clinical care and treatment of complications, with the potential for long term benefits for the patient. ${ }^{19} \mathrm{~A}$ high proportion of ADPKD patients suffering from intracranial haemorrhage have untreated or poorly treated hypertension. ${ }^{20}$ Considering that in this family two out of nine patients with a known history suffered from subarachnoid haemorrhages, and taking into account that seven out of eight patients have hypertension, early detection and treatment of high blood pressure may well decrease the risk of intracranial bleeding. ${ }^{19}$

In conclusion, segregation analysis with tightly linked flanking DNA markers enabled us to detect the ADPKD chromosome in the patient, confirming the clinical diagnosis of the adult type disease at the genetic level.

We thank the members of the family who collaborated in this study. The probes on chromosome $16 \mathrm{p}$ were made available by Dr $M$ Breuning through the European Concerted Action 'Towards prevention of kidney failure caused by inherited polycystic kidney disease'. Primer sequences for SM7 PCR were kindly provided by Dr P Harris. Probe YNH24 was kindly provided by Dr Y Nakamura. This work was supported by the Italian National Research Council (CNR) Target Projects 'Biotechnology and Bioinstrumentation' and 'Genetic Engineering', and by a Veneto Region Sanitary Research Grant.

1 Reeders ST, Breuning MH, Davies KE, et al. A highly polymorphic DNA marker linked to adult polycystic kidney disease on chromosome 16. Nature 1985;317:542-

2 Pieke SA, Kimberling WJ, Kenyon JB, Gabow P. Genetic heterogeneity of polycystic kidney disease: an estimate of heterogeneity of polycystic kidney disease: an estimate of Am $\mathcal{f}$ Hum Genet 1989;45:58A.

3 Turco A, Peissel B, Gammaro L, Maschio G, Pignatti PF. Linkage analysis for the diagnosis of autosomal dominant polycystic kidney disease, and for the determination of genetic heterogeneity in Italian families. Clin Genet 1991;40:287-97.

4 Norby S, Schwartz M. Possible locus for polycystic kidney disease on chromosome 2. Lancet 1990;336:323-4.

5 Lazarou LP, Davies F, Sarfarazi M, Coles GA, Harper PS. Adult polycystic kidney disease and linked RFLPs at the $\alpha$ globin locus: a genetic study in the South Wales population. F Med Genet 1987;24:466-73.

6 Pretorius DH, Lee ME, Manco-Johnson ML, Weingast GR, Sedman AB, Gabow PA. Diagnosis of autosomal dominant polycystic kidney disease in utero and in the dominant polycystic kidney disease in utero and

7 Ceccherini I, Lituania M, Cordone MS, et al. Autosomal dominant polycystic kidney disease: prenatal diagnosis by DNA analysis and sonography at 14 weeks. Prenat Diagn DNA analysis

8 Thomson PD, Isdale JM. Infantile polycystic kidney disease (IPKD). Kidney Int 1984;26:898.

9 Ramsay M, Reeders ST, Thomson PD, et al. Mutations for the autosomal recessive and autosomal dominant forms of polycystic kidney disease are not allelic. Hum Genet 1988;79:73-5.

10 Breuning MH, Snijdewint FGM, Brunner H, et al. Map of 16 polymorphic loci on the short arm of chromosome 16 close to the polycystic kidney disease gene (PKD1). 7 Med Genet 1990;27:603-13.

11 Harris P, Thomas S, Ratcliffe PJ, Breuning MH, Coto E, Lopez-Larrea C. Rapid genetic analysis of families with polycystic kidney disease 1 by means of a microsatellite molycystic kidney disease 1 by

12 Gagnadoux MF, Habib R, Levy M, Broyer M. Polycystic kidney disease in childhood. In: Sessa A, Conte F, Serbelkidney disease in childhood. In: Sessa A, Conte F, SerbelMilano: Wichtig Editore, 1989:23-8.

13 Grantham JJ. Polycystic kidney disease: neoplasia in disguise. Am f Kidney Dis 1990;2:110-16.

14 Bernstein J. Polycystic disease. In: Edelman CM, ed. Pediatric kidney disease. Boston: Little, Brown and Co, 1978:557-70

15 Loh JP, Haller JO, Kassner EG, Aloni A, Glassberg K. Dominantly-inherited polycystic kidneys in infants: association with hypertrophic pyloric stenosis. Pediatr Radiol 1977;6:27-30.

16 Zerres K, Hansmann M, Knöpfle G, Stephan M. Prenatal diagnosis of genetically determined early manifestation of autosomal dominant polycystic disease? Hum Genet 1985;71:368-9.

17 Gillespie GAJ, Somlo S, Germino GG, Weinstat-Saslow D, Reeders ST. CpG island in the region of an autosomal dominant polycystic kidney disease locus defines the $5^{\prime}$ end of a gene encoding a putative proton channel. Proc Natl Acad Sci USA 1991;88:4289-93.

18 Risch N. Genetic linkage: interpreting lod scores. Science 1992;255:803-4.

19 Ravine D, Walker RG, Gibson RN, Sheffield LJ, KincaidSmith P, Danks DM. Treatable complications in undiaSmith P, Danks DM. Treatable complications in undia-
gnosed cases of autosomal dominant polycystic kidney gnosed cases of autosomal domin
disease. Lancet 1991;337:127-9.

20 Ryu SJ. Intracranial hemorrhage in patients with polycystic kidney disease. Stroke 1990;21:291-4. 